\title{
CONGENITAL DIAPHRAGMATIC HERNIA ASSOCIATED WITH FRYNS SYNDROME -AN AUTOPSY STUDY
}

Surekha Ulhas Arakeri, Jaya Manchanda.

1. Professor, Department of Pathology, BLDEU'S Shri B. M. Patil Medical College \& Research Centre, Bijapur.

2. Postgraduate Student, Department of Pathology, BLDEU'S Shri B. M. Patil Medical College \& Research Centre, Bijapur.

\section{CORRESPONDING AUTHOR}

Dr. Surekha Ulhas Arakeri, Professor, Department of Pathology, BLDEU's Shri B. M. Patil Medical College

\& Research Centre, Bijapur

E-mail: drsuarakeri@hotmail.com, Ph: 009198457678444.

ABSTRACT: BACKGROUND: Congenital Diaphragmatic Hernia (CDH) is an anatomical defect that permits abdominal contents inside the thoracic cavity and affects 1 in 2000 to 5000 children each year and is associated with high morbidity and mortality. CDH may be associated with other anomalies like dysmorphic features, genitourinary, musculoskeletal, cardiovascular, neurological and gastrointestinal malformations.CDH is a devastating birth defect that can occur in isolation or part of complex malformation of various syndromes. Here we report an autopsy study of CDH with Fryns syndrome. CASE PRESENTATION: An autopsy study of still born foetus born to a 35-year old, fifth gravida presented with features of $\mathrm{CDH}$ with left lung hypoplasia, hypoplasia of distal parts of digits of upper and lower limbs and dysmorphic features. CONCLUSION: CDH is a life threatening pathology in infants and a major cause of death due to pulmonary hypoplasia and pulmonary hypertension. An early diagnosis with increased understanding of this disease is a crucial factor for a timely approach to manage the critically ill infant and to offer potential treatment for improved outcome and substantial reduction in morbidity.

KEY WORDS: Congenital diaphragmatic hernia (CDH), Fryn syndrome, pulmonary hypoplasia, Hypoplasia of digits.

INTRODUCTION: Congenital Diaphragmatic Hernia (CDH) is a life threatening congenital anomaly which needs intensive neonatal care and is associated with high morbidity and mortality with an incidence ranging between 1 in 2000 to 5000 per year. CDH may be associated with other congenital anomalies like dysmorphic features, genitourinary, musculoskeletal, cardiovascular, neurological and gastrointestinal malformations in $30 \%$ to $40 \%$ of the cases. These associated anomalies acts as major factor influencing the outcome of the affected patients. According to some authors, the most commonly associated major congenital anomaly was neural tube defect followed by cardiac and chromosomal anomalies. Severe pulmonary hypoplasia was the major cause of mortality in stillborn babies and in all infants of $\mathrm{CDH}$ dying within one week of birth. ${ }^{1,2} \mathrm{CDH}$ can occur in isolation or as part of a various syndromes such as Pallister-Killian syndrome(PKS), Ghersoni-Baruch syndrome, WAGR syndrome, Fryn syndrome, Denys-Dash syndrome, Brachman-De Lange syndrome and WolfHirschhorn syndrome. Fryns syndrome is a rare autosomal recessive disorder characterized by diaphragmatic hernia and multiple anomalies². 
CASE SUMMARY: A 35-year old, fifth gravida presented with 24 week of gestation. She gave past obstetric history of one abortion and history of neonatal death of one child. Antenatal ultrasound scan was performed which revealed congenital anomaly of diaphragm. Based on ultrasound findings, radiological diagnosis of $\mathrm{CDH}$ was done for which therapeutic abortion was performed in the present pregnancy at 24 week of gestation, and a still born foetus was delivered which was sent for post mortem study.

AUTOPSY FINDINGS: Received a male foetus with placenta and attached umbilical cord. Placenta was $275 \mathrm{gm}$ in weight and measured $16 \times 10 \times 3 \mathrm{~cm}$. Weight of the foetus was $600 \mathrm{gm}$. Crown rump and crown heel length was 17 and $29 \mathrm{~cm}$ respectively. Head circumference, chest circumference and abdominal girth were 23, 20 and $18 \mathrm{~cm}$ respectively. External examination showed widely spaced protuberant eyes, broad and depressed nasal bridge, extra space between nose and upper lip, large mouth, small chin and hypoplasia of distal parts of digits of upper and lower limb (Figure 1). On cut open, it was found that left part of the diaphragm was deficient \& left lobe of liver, spleen and coils of intestine were protruded through this deficiency in the thoracic cavity (Figure 1). Left lung weighed $4 \mathrm{gms}$ and measured $1.5 \times 1.5 \times 0.5 \mathrm{~cm}$; Right lung weighed $6 \mathrm{gms}$ and measured $3 \times 2 \times 0.5 \mathrm{~cm}$ (Figure 2, Inset). Lung weight to body weight (LW: BW) ratio was 0.01 . Heart, liver, spleen, right and left kidneys were normal. Microscopic examination of right lung showed thick walled lung alveoli lined by cuboidal epithelium. Dense connective tissue and bronchial cartilage was noted in inter and intralobular connective tissue. In the left lung features as described above with decrease in number of alveoli were noted. Based on above findings, a diagnosis of CDH associated with dysmorphic facial features, hypoplasia of digits and pulmonary hypoplasia suggestive of Fryns syndrome was given.

DISCUSSION: Development of the diaphragm is divided into two phases such as development of the diaphragmatic pericardium and development of the pleural cavity and closure of the pleuroperitoneal canal (PPC). General hypothesis is that the defect in CDH may results from failure of complete closure of the PPC at the embryonic period of $8^{\text {th }}$ to $10^{\text {th }}$ gestational week. Association of $\mathrm{CDH}$ with various congenital anomalies, varying pathological patterns and clinical presentation suggests that it is a result of multiple, complex developmental abnormalities. ${ }^{1} \mathrm{CDH}$ is a cardinal feature of Fryns syndrome. ${ }^{3}$ Studies indicate that Fryns syndrome is diagnosed in $1.3 \%$ to $10 \%$ of all the cases having $\mathrm{CDH}$. This syndrome is generally difficult to diagnose..$^{3,4}$ Diagnostic criteria for Fryns syndrome reformulated by Lin AE et al ${ }^{5}$ were 4 out of following 6 symptom groups such as diaphragmatic defect, facial characteristics, distal digital hypoplasia, pulmonary hypoplasia, parental consanguity and other associated anomalies such as cardiovascular malformation, renal dysplasia/renal cortical cysts, gastrointestinal malformation, genital malformation should be present. ${ }^{4,5}$ In the present case, 4 symptom groups such as $\mathrm{CDH}$, dysmorphic facial features, pulmonary hypoplasia and distal digital hypoplasia were seen. Hence this case was concluded as Fryns syndrome. LW: BW ratio is the most widely used parameter for diagnosis of pulmonary hypoplasia. Pathologic postmortem diagnosis of pulmonary hypoplasia was suggested when the LW: BW was found to be less than $0.12 .{ }^{6}$ Based on this finding, diagnosis of pulmonary hypoplasia was made in the present case. Considerable phenotypic overlap was noted between Fryns and PKS. In both syndromes CDH, coarse facial features and minor limb anomalies were seen. Features more common for, Fryns syndrome are $\mathrm{CDH}$, cleft palate, and distal phalange and/or nail hypoplasia, cardiovascular malformations, and renal malformations. Features more common for PKS are high forehead, streaky skin hyper 
pigmentation, and sparseness of hair bi-temporally. ${ }^{7}$ In the present case, $\mathrm{CDH}$ was associated with pulmonary hypoplasia, dysmorphic facial features and distal digital hypoplasia hence the case was concluded as Fryns syndrome. Association of diaphragmatic defects and upper limb anomalies were not reported commonly.8-10 McCredie and Reid ${ }^{8}$ reported 4 single cases of diaphragmatic defect associated with limb anomalies. The limb defects ranged from a radial hypoplasia to a transverse deficiency, with a block of bone distal to the hummers. Lerone et $\mathrm{al}^{9}$ reported a case of left congenital diaphragmatic hernia associated with ipsilateral thumb hypoplasia. A similar case of congenital left diaphragmatic hernia with ipsilateral thumb hypoplasia and absent radius was reported by Wallerstein et al.10 In the present case, CDH is associated with hypoplasia of distal parts of digits of upper \& lower limbs which is one of the uncommon finding.

CONCLUSION: Incidence of mortality associated with CDH will become apparent only when the autopsy study of infant and fetuses that have died with a diagnosis of $\mathrm{CDH}$ will be included in the analysis. ${ }^{1}$ In this case, abortion of previous pregnancy and neonatal death of sibling may be due to presence of $\mathrm{CDH}$ and associated syndrome. As Fryns syndrome is autosomal recessive disorder, autopsy study of present case will assist in counseling to the parents about recurrence of the disease in next pregnancies and advising regular antenatal ultrasound scan and screening for maternal serum Alpha fetoprotein assay at 13 weeks in next pregnancy.

\section{REFERENCES:}

1. Arafah M, Boqari DT, Alsaad KO. Left-sided congenital diaphragmatic hernia with multiple congenital cardiac anomalies, hernia sac, and microscopic hepatic heterotopia: A Case Report. Pathology Res Int 2011; 96:710 -7.

2. Tovar JA. Orphanet Journal of Rare Diseases 2012; 7:1 doi: 10.1186/1750-1172-7-1. Available at: http://www.ojrd.com/content/7/1/1

3. Slavotinek A, Lee SS, Davis R, Shrit A, Leppig KA, Rhim J et al. Fryns syndrome phenotype caused by chromosome microdeletions at 15q26.2 and 8p23.1. J Med Genet 2005; 42:730736.

4. Slavotinek A. Fryns syndrome. In: Pagon RA, Bird TD, Dolan CR, Stephens K, Adam MP editors. GeneReviews ${ }^{\mathrm{TM}}$ [Internet]. Seattle (WA): University of Washington, Seattle; 2007 [cited 2010 Jun 1]. Available from: http://www.ncbi.nlm.nih.gov/books/NBK1459/

5. Lin AE, Pober BR, Mullen MP, Slavotinek AM. Cardiovascular malformations in Fryns syndrome: is there a pathogenic role for neural crest cells. Am J Med Genet A 2005; 139:186-93.

6. Askenazi SS, Perlman M. Pulmonary hypoplasia: lung weight and radial alveolar count as criteria of diagnosis. Arch Dis Child 1979; 54:614-618.

7. Pober BR, Russell MK, Ackerman KG. Congenital Diaphragmatic Hernia Overview. In: Pagon RA, Bird TD, Dolan CR, Stephens K, Adam MP editors. Gene Reviews ${ }^{\mathrm{TM}}$ [Internet]. Seattle (WA): University of Washington, Seattle; 1993 [cited 2010 Mar 16]. Available from: http://www.ncbi.nlm.nih.gov/books/NBK1359/

8. Mccredie J, Reid IS. Congenital diaphragmatic hernia associated with homolateral upper limb malformation. J Pediatr 1978; 92:762-5. 
9. Lerone M, Soliani M, Corea D, Romeo G, Martucciello G, Silengo MC. Congenital diaphragmatic hernia associated with ipsilateral upper limb reduction defects: report of a case with thumb hypoplasia. Am J Med Genet 1992; 44:827-9.

10. Wallestein R, Wallerstein DF, Trauffer P, Desposto F. Congenital diaphragmatic hernia and ipsilateral limb reduction defect: a new case, longterm follow-up and review of the literature. Clin Dysmorphol 1997; 6:257-61.

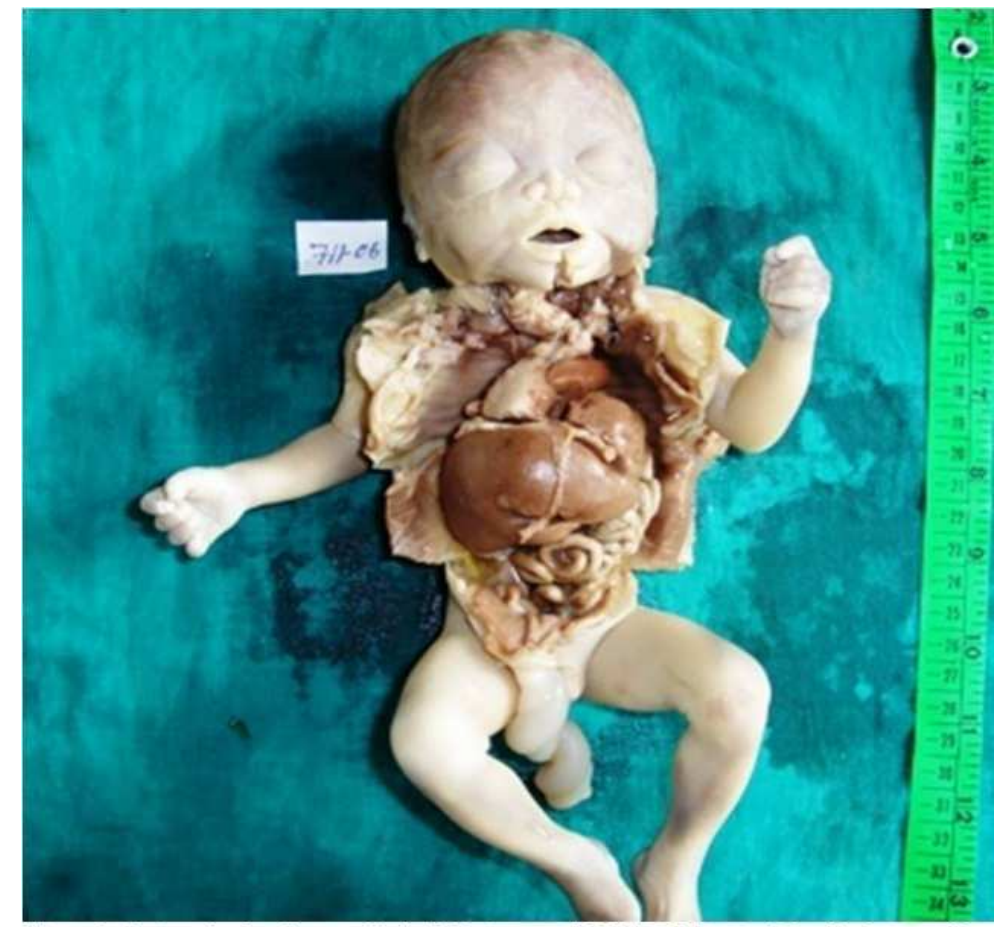

Figurel: Foetus showing dysmorphic facial features and deficient left part of the diaphragm with protrusion of left lobe of liver, spleen and coils of intestine in thoracic cavity.

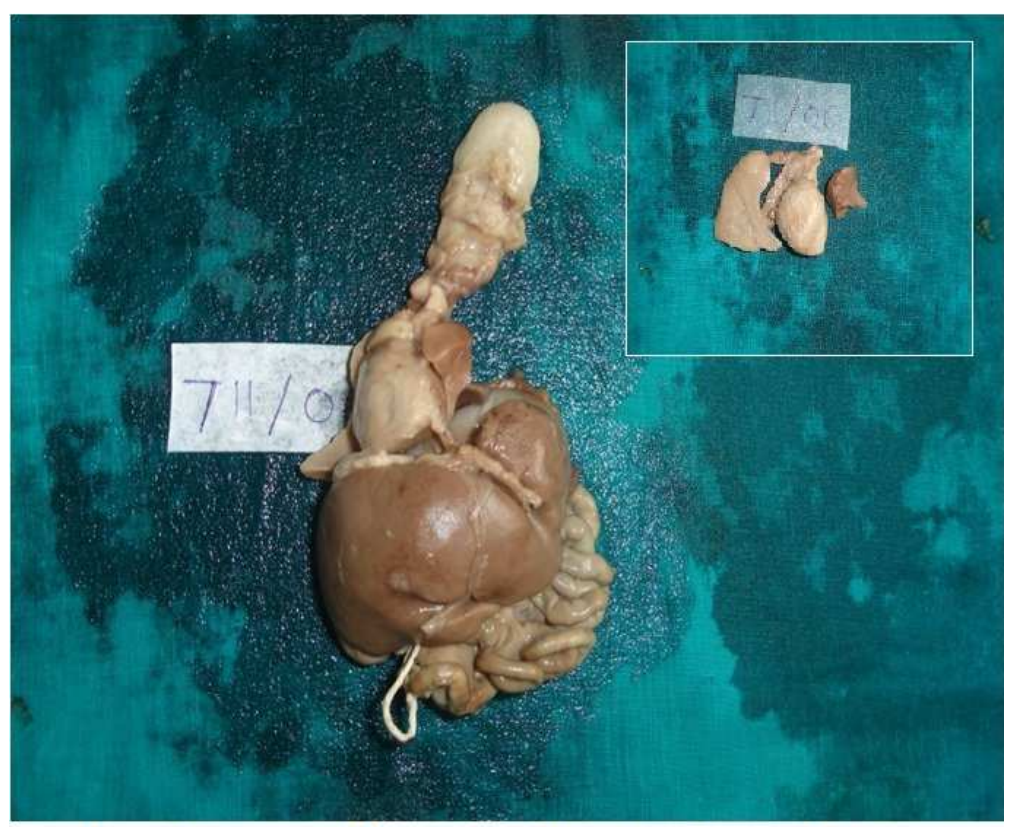

Figure 2: En-block removal of organs. Inset: Right lung, heart \& hypoplastic left lung 